\title{
CORRELAÇÃO ENTRE LEITURA LASER, PERMEABILIMETRO DE BLAINE E PENEIRAMENTO PARA SUPERFÍCIE ESPECÍFICA E GRANULOMETRIA DE MINÉRIO DE FERRO*
}

Gilvandro Bueno

William Wagner Dettoni Regattieri2 Caio Daher Carneiro Gamberini ${ }^{3}$

\section{Resumo}

Os controles dos processos de cominuição estão normalmente associados à redução de granulometria e geração de superfície específica, usualmente utiliza-se peneiramento para medição de granulometria e permeabilímetro de Blaine para superfície específica, estes métodos são largamente utilizados para este fim. $O$ método on line por difratômetros a laser também pode ser empregado para estas medições na indústria, como se trata de uma tecnologia recentemente adaptada para ao processo de Pelotização, foi necessário validar o equipamento e determinar equações de correlação de leitura com os equipamentos existentes. $O$ trabalho consistiu em realizar uma série de amostragens cujas amostras foram analisadas no equipamento industrial a laser, em seguida analisadas em laboratório. As equações de correlações obtidas foram inseridas no equipamento industrial de medição on line por laser tornando a leitura familiar aos obtidos pelas análises de laboratório, onde foi possível garantir confiabilidade para tomadas de decisões.

Palavras-chave: Laser Vs Permeabilímetro e peneiramento; Superfície especifica.

\section{CORRELATION BETWEEN LASER READING, BLAINE AIR PERMEABILITY APPARATUS AND SCREENING FOR SPECIFIC SURFACE AND PARTICLE SIZE OF IRON ORE}

\begin{abstract}
The control process of comminution are normally associated with reduction size and generating specific surface, screening is usually used to size measuring and Blaine Air Permeability Apparatus to measure specific surface, this methods are reliable and widely used for this purpose. The online method by laser diffraction can be employed for this measurement in industry, since this is a newly adapted to the pelletizing process technology, it was necessary to validate the equipment and determine the correlation equations reading with existing equipment. The study consisted of performing a series of samples whose samples were analyzed in the industrial laser equipment then analyzed in the laboratory. These equations were incorporated in the industrial measurement equipment online laser making family reading those obtained by laboratory analysis, where it was possible to ensure reliability for decision making
\end{abstract}

Keywords: Laser vs. Air permeability apparatus and screening; Blaine; Particle size.

Engenheiro Metalurgista, Engenheiro de Processo Máster, Vale, Vitória, ES, Brasil.

Técnico de Metalurgia, Técnico Especializado de Processo, Vale, Vitória, ES, Brasil.

Estudante de Engenharia, $10^{\circ}$ Período de Engenharia de Produção, IFES, Vitória, ES, Brasil.

* Contribuição técnica ao $44^{\circ}$ Seminário de Redução de Minério de Ferro e Matérias-primas, $15^{\circ}$ Simpósio Brasileiro de Minério de Ferro e $2^{\circ}$ Simpósio Brasileiro de Aglomeração de Minério de Ferro, 15 a 18 de setembro de 2014, Belo Horizonte, MG, Brasil. 


\section{INTRODUÇÃO}

No processo de aglomeração para formação de pelotas, forças de adesões capilares são importantes mecanismos para garantir uma boa resistência da pelota crua. Para maximizar estas forças é necessário um controle apurado tanto de granulometria quanto de superfície específica do minério de ferro.

Os métodos de peneiramento e permeabilímetro de Blaine são largamente utilizados para mensuração da distribuição granulométrica e de superfície específica respectivamente. A distribuição granulométrica é expressa em percentual retido ou passante em determinada malha de peneira e a superfície específica representa a soma da área das partículas em uma determinada massa, normalmente expressa em $\mathrm{cm}^{2} / \mathrm{g}$ ou $\mathrm{m}^{2} / \mathrm{kg}$. Para evitar uma quantidade excessiva de trabalho e tempo, em alguns processos somente a porção menor que $0,045 \mathrm{~mm}$ é determinada por peneiramento e expressa em percentual passante. A faixa onde se encontra os micro finos $(<0,02 \mathrm{~mm})$ é determinada através permeabilidade da amostra, preparada de acordo com especificações e mensurada em superfície especifica via permeabilímetro de Blaine.

A tecnologia de medição por difratômetros a laser também pode ser empregada para a medição da distribuição granulométrica e de superfície específica em vários ramos industriais. Devido à natureza irregular das partículas, o tamanho da partícula medido por este método é definido como tamanho equivalente à esfera. Este método produz resultados rápidos e vem ganhando espaço nos processos industriais, no entanto como se trata de uma tecnologia recentemente adaptada para ao processo de pelotização, foi necessário validar o equipamento e determinar equações de correlação entre os equipamentos já existentes.

A metodologia do trabalho consistiu em realizar uma série de amostragens cujas amostras foram analisadas primeiramente no equipamento industrial em campo a laser e em seguida levadas ao laboratório para análise de bancada com a mesma tecnologia laser e analisadas também em peneiras para determinação da granulometria passante em $0,045 \mathrm{~mm}$ e permeabilímetro de Blaine para determinação da superfície específica. De posse dos resultados pôde-se estabelecer equações de correlação de leitura entre os métodos, de modo a não haver perda na precisão de análise e demonstração dos resultados. Estas equações foram inseridas no equipamento industrial de medição on line por laser tornando a leitura familiar aos resultados obtidos pelas análises de laboratório, onde foi possível garantir confiabilidade para tomadas de decisões no controle de processo da moagem.

\section{MATERIAIS E MÉTODOS}

O trabalho foi realizado utilizando-se duas frentes: uma através da compilação dos resultados analisados pelo difratômetros industrial e outra através de amostragem, tratamento das mostras em laboratório, análises e compilação dos resultados. $O$ equipamento industrial além de realizar as análises também serviu para coleta de amostra para posterior análise em laboratório. Este procedimento garantiu que a mesma amostra fosse analisada por métodos distintos verificando-se a calibração do equipamento industrial, bem como se existe uma correlação entre os valores analisados por este comparado aos métodos tradicionais de análise em laboratório. A figura 1 abaixo descreve a sequência utilizada no trabalho.

\footnotetext{
* Contribuição técnica ao $44^{\circ}$ Seminário de Redução de Minério de Ferro e Matérias-primas, $15^{\circ}$ Simpósio Brasileiro de Minério de Ferro e $2^{\circ}$ Simpósio Brasileiro de Aglomeração de Minério de Ferro, 15 a 18 de setembro de 2014, Belo Horizonte, MG, Brasil.
} 


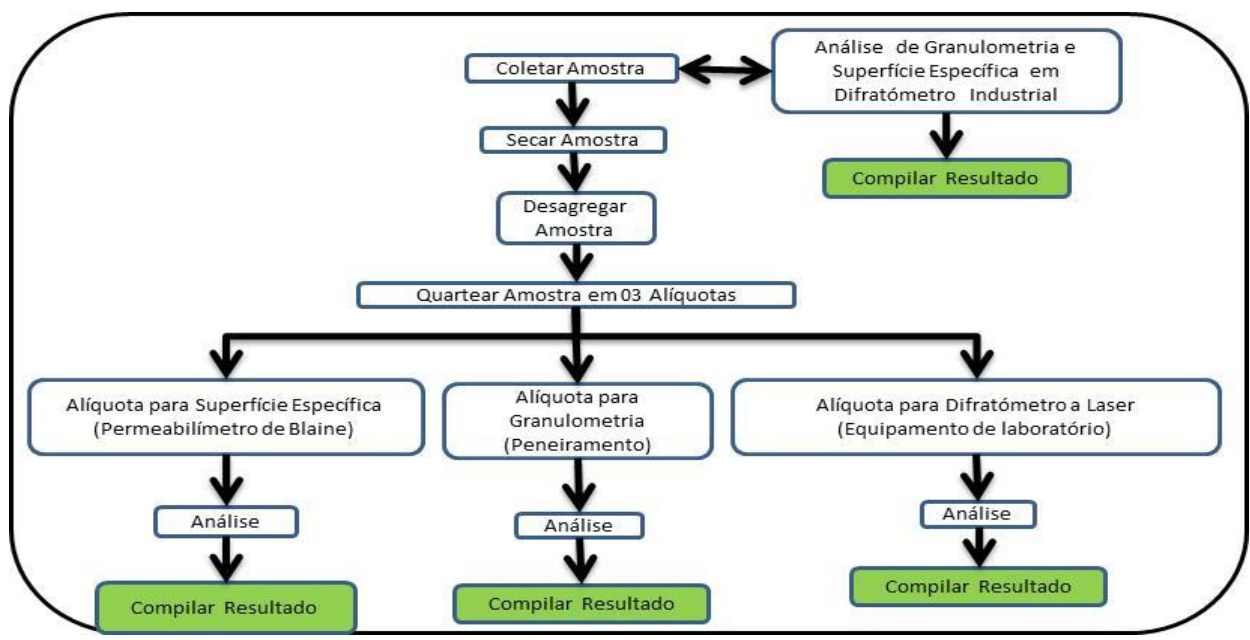

Figura 1. Fluxograma com a sequência de trabalho

\subsection{Amostragem}

O equipamento industrial de análise de granulometria e superfície especifica por difratômetro a laser, além de direcionar a amostra colhida para realizar as análises, este possui também uma derivação para coleta de amostra com a finalidade de realizar sua calibração. Esta derivação foi utilizada para coleta das amostras para serem analisadas no laboratório.
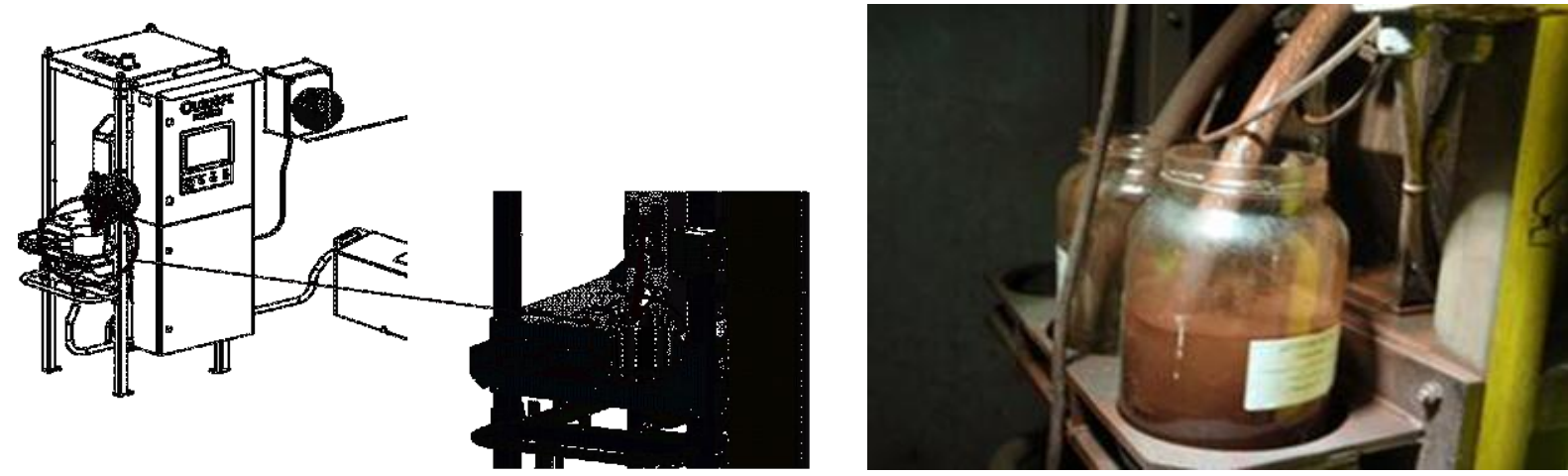

Figura 2. Ponto de coleta de amostra no equipamento industrial

Para realização do trabalho foram coletadas amostras variando-se a taxa de alimentação dos moinhos em $270 \mathrm{t} / \mathrm{h}, 300 \mathrm{t} / \mathrm{h}$ e $340 \mathrm{t} / \mathrm{h}$, estes valores foram definidos tomando-se como referencia as taxas mínimas, médias e máximas normalmente operadas nestes moinhos. Esta variação teve como objetivo proporcionar de forma forçada uma variação nas granulometrias e superfícies especifica analisadas de modo a gerar uma maior distribuição de pontos ao longo das curvas de correlações. Esta condição de teste foi repetida 06 vezes para cada moinho tomando-se o cuidado de não realizar 02 amostras com a mesma taxa sequencialmente no mesmo moinho, ao todo foram geradas 36 amostras para realização do trabalho. Entre uma amostra e outra foi aguardado um intervalo de no mínimo 1 hora para que houvesse estabilização do circuito com a nova taxa de alimentação. Este procedimento foi adotado tomando-se como referencia um trabalho semelhante realizado anteriormente em outra planta de moagem.

Conforme mencionado anteriormente 0 equipamento industrial realiza simultaneamente a análise e coleta de amostra externa, os valores analisados pelo

* Contribuição técnica ao 44ํㅗㄴ Seminário de Redução de Minério de Ferro e Matérias-primas, 15은 Simpósio Brasileiro de Minério de Ferro e $2^{\circ}$ Simpósio Brasileiro de Aglomeração de Minério de Ferro, 15 a 18 de setembro de 2014, Belo Horizonte, MG, Brasil. 
equipamento durante a amostragem foram compilados para posterior comparação e geração da curva de calibração entre este método e as análises de laboratório.

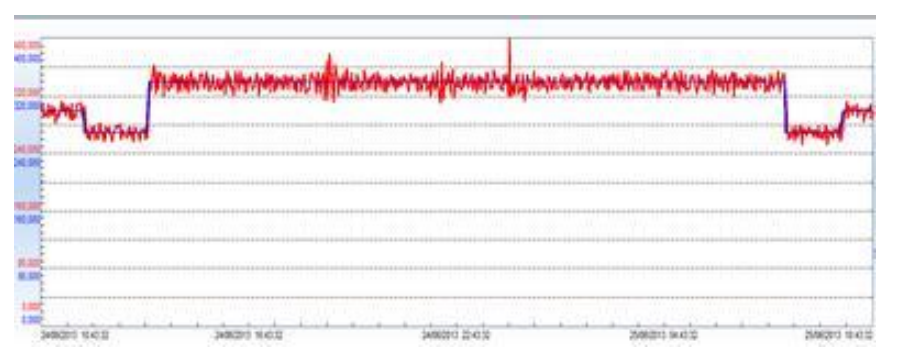

Figura 3. Taxas de alimentação dos moinhos durante o teste

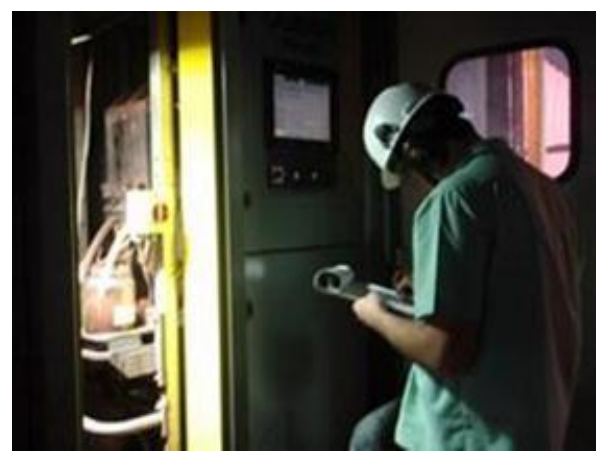

Figura 4. Compilação dos resultados analisados pelo equipamento industrial

Tabela 1. Sequência de amostragem em diferentes taxas de alimentação da moagem

\begin{tabular}{|c|c|c|c|c|c|c|}
\hline \multicolumn{6}{|c|}{ Sequência do Teste de Calibração e Correlação } & \\
\hline 1 & 2 & \begin{tabular}{|c|}
3 \\
\end{tabular} & & & & \\
\hline 270 & 300 & 340 & & & & \\
\hline Horário & $4 M 6 A(t / h)$ & № Amostra & Status & $4 \mathrm{M} 6 \mathrm{~B}(\mathrm{t} / \mathrm{h})$ & \begin{tabular}{|l|} 
№ Amostra \\
\end{tabular} & Status \\
\hline 10 & 300 & 1 & & 300 & 2 & \\
\hline 20 & 270 & 3 & & 340 & 4 & \\
\hline 3은 & 340 & 5 & & 300 & 6 & \\
\hline 4으 & 270 & 7 & & 270 & 8 & \\
\hline 5으 & 300 & 9 & & 340 & 10 & \\
\hline 6o & 340 & 11 & & 270 & 12 & \\
\hline 70 & 270 & 13 & & 300 & 14 & \\
\hline 80 & 340 & 15 & & 340 & 16 & \\
\hline 9o & 300 & 17 & & 270 & 18 & \\
\hline 100 & 270 & 19 & & 300 & 20 & \\
\hline 11응 & 300 & 21 & & 340 & 22 & \\
\hline 120 & 340 & 23 & & 300 & 24 & \\
\hline 130 & 270 & 25 & & 270 & 26 & \\
\hline 140 & 300 & 27 & & 340 & 28 & \\
\hline 150 & 340 & 29 & & 270 & 30 & \\
\hline 160 & 270 & 31 & & 300 & 32 & \\
\hline 170 & 340 & 33 & & 340 & 34 & \\
\hline 180 & 300 & 35 & & 270 & 36 & \\
\hline
\end{tabular}

* Contribuição técnica ao 44 Seminário de Redução de Minério de Ferro e Matérias-primas, $15^{\circ}$ Simpósio Brasileiro de Minério de Ferro e $2^{\circ}$ Simpósio Brasileiro de Aglomeração de Minério de Ferro, 15 a 18 de setembro de 2014, Belo Horizonte, MG, Brasil. 


\subsubsection{Difratômetro a laser industrial}

O Difratômetro é um instrumento on line de medição da granulometria e superfície específica das partículas diluídas na polpa de minério. O princípio utilizado é difração de luz laser, com o cálculo das dispersões para análise da distribuição granulométrica em diversas faixas $(1 \mu \mathrm{m}$ até $500 \mu \mathrm{m})$.

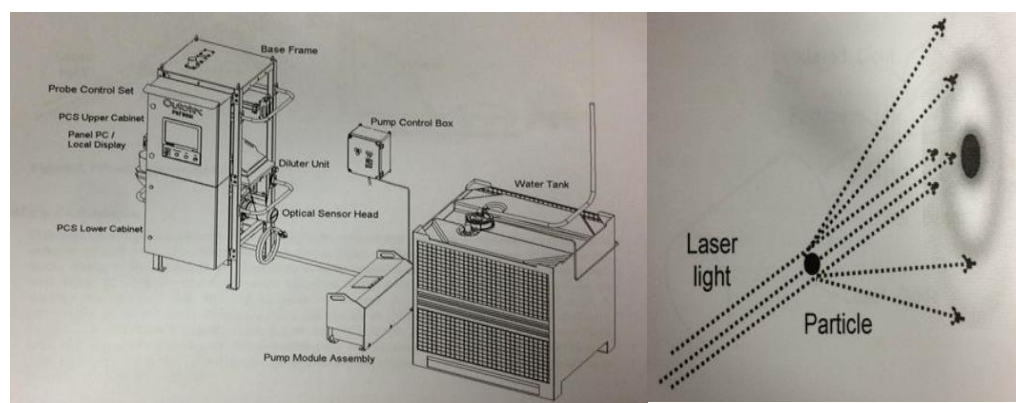

Figura 8. Difratômetro a laser

\subsubsection{Difratômetro a laser de laboratório}

O difratômetro a laser de laboratório utiliza o mesmo princípio de funcionamento do equipamento industrial, este equipamento foi utilizado para análise de granulometria e superfície específica com o objetivo de verificar a calibração do equipamento industrial, o equipamento utilizado nas análises de laboratório foi fabricado pela Malvern.

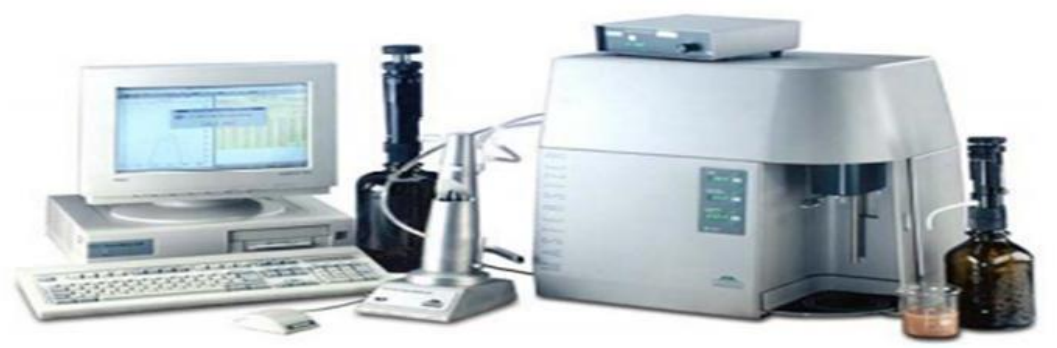

Figura 9. Difratômetro a laser de laboratório

\subsubsection{Peneirador aerodinâmico}

É uma peneira que tem uma força interna gerada por um vácuo, que auxilia no peneiramento, método utilizado no laboratório para medição de granulometria. Este método é utilizado pelo laboratório para as análise de rotina, o objetivo desta análise foi procurar estabelecer uma correlação entre os resultados de granulometria deste método aos resultados do equipamento industrial de análise por difratômetro a laser.

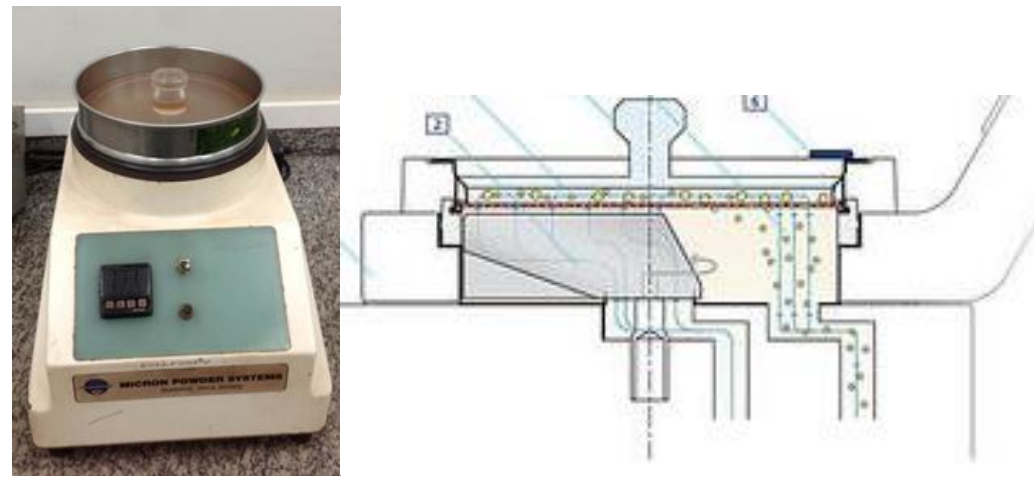

Figura 10. Peneirador aerodinâmico

\footnotetext{
* Contribuição técnica ao 44 Seminário de Redução de Minério de Ferro e Matérias-primas, $15^{\circ}$ Simpósio Brasileiro de Minério de Ferro e $2^{\circ}$ Simpósio Brasileiro de Aglomeração de Minério de Ferro, 15 a 18 de setembro de 2014, Belo Horizonte, MG, Brasil.
} 


\subsubsection{Permeabilímetro de Blaine /Fisher}

Estes equipamentos de análise de superfície específica são baseados no princípio de permeabilidade do ar que passa por uma coluna compacta. No aparelho, lê-se o diâmetro médio da partícula, numa escala de 0,2 a $50 \mu \mathrm{m}$. Este método é utilizado pelo laboratório para as análise de rotina, o objetivo desta análise foi procurar estabelecer uma correlação entre os resultados de superfície específica deste método aos resultados do equipamento industrial de análise por difratômetro a laser. Como todos os testes foram realizados no laboratório da planta piloto e esta unidade não opera com o equipamento Blaine optou-se então, em realizar o teste com o equipamento Fisher. Esta decisão não acarreta prejuízos aos resultados encontrados, uma vez que o equipamento Fisher já opera com curva de transformação para Blaine.

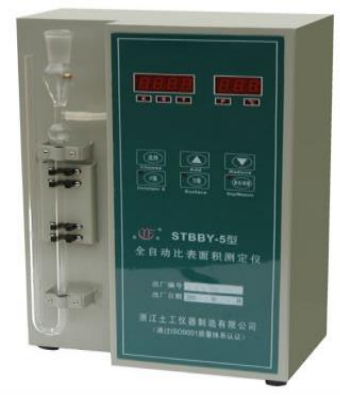

Figura 11. Permeabilímetro de Blaine

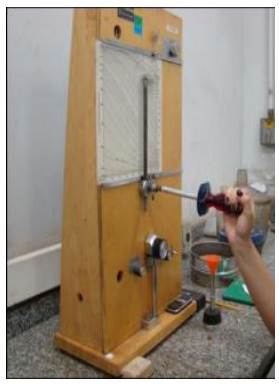

Figura 12. Permeabilímetro de Fisher

\subsection{Tratamento Estatístico}

Em pesquisas, frequentemente, procura-se verificar se existe relação entre duas ou mais variáveis, isto é, saber se as alterações sofridas por uma das variáveis são acompanhadas por alterações nas outras, a verificação da existência e do grau de relação entre as variáveis é o objeto de estudo da correlação.

\subsubsection{Correlação linear simples}

Uma vez caracterizada a relação entre as variáveis, procura-se descrevê-la sob forma matemática, através de uma função. É conveniente usar para medida de correlação, o coeficiente de correlação linear de Pearson, como estimador de $r_{x y}$.

$\mathrm{O}$ coeficiente de correlação $r_{x y}$ linear é um número puro que varia de $-1 \mathrm{a}+1$ e sua interpretação dependerá do valor numérico e do sinal, como segue:

A regra básica dos níveis de resposta de r para um teste de hipótese com correlação $r_{x y}$ é:

- $r_{x y}=-1-$ Correlação perfeitamente negativa;

- $-1<r_{x y}<0-$ Correlação negativa;

- $r_{x y}=0-$ Correlação nula;

- $0<\mathrm{r}_{\mathrm{xy}}<1$ - Correlação positiva;

- $r_{x y}=1-$ Correlação fortemente positiva;

- $0,2<\mathrm{r}_{\mathrm{xy}}<0,4-$ Correlação fraca*

- $0,4<\mathrm{r}_{\mathrm{xy}}<0,7$ - Correlação moderada*

- $0,7<\mathrm{r}_{\mathrm{xy}}<0,9$ - Correlação forte*

*possui o mesmo significado para os casos negativos ou positivos.

* Contribuição técnica ao 44 Seminário de Redução de Minério de Ferro e Matérias-primas, 15ㅇ Simpósio Brasileiro de Minério de Ferro e 2o Simpósio Brasileiro de Aglomeração de Minério de Ferro, 15 a 18 de setembro de 2014, Belo Horizonte, MG, Brasil. 


\subsubsection{Coeficiente de determinação $R^{2}$}

Indica a proporção de variação da variável independente que é explicada pela variável dependente, ou seja, é uma ferramenta que avalia a qualidade do ajuste.

Quanto mais próximo da unidade o $\mathrm{R}^{2}$ estiver, melhor a qualidade do ajuste. $\mathrm{O}$ seu valor fornece a proporção da variável $Y$ explicada pela variável $X$ através da função ajustada.

\section{RESULTADOS E DISCUSSÃO}

As análise realizadas com as amostras geraram bancos de dados conforme tabelas 2 e 3 abaixo que serviram de suporte para este trabalho.

Tabela 2. Valores para verificação de calibração

\begin{tabular}{|c|c|}
\hline $\begin{array}{c}\text { S.E. } \\
\left(\mathrm{cm}^{2} / \mathrm{g}\right) \\
\text { Malvern }\end{array}$ & $\begin{array}{l}\mathrm{SE}\left(\mathrm{m}^{2} / \mathrm{kg}\right) \\
\text { Industrial }\end{array}$ \\
\hline 1260 & 122,3 \\
\hline 1160 & 111,3 \\
\hline 1050 & 101,0 \\
\hline 1370 & 132,2 \\
\hline 1120 & 104,8 \\
\hline 1230 & 121,3 \\
\hline 1360 & 136,2 \\
\hline 1250 & 122,6 \\
\hline 1310 & 130,4 \\
\hline 1060 & 100,7 \\
\hline 1150 & 111,5 \\
\hline 1260 & 131,6 \\
\hline 1130 & 112,2 \\
\hline 1070 & 100,5 \\
\hline 1310 & 132,0 \\
\hline 1150 & 113,5 \\
\hline 1250 & 127,8 \\
\hline 1380 & 140,3 \\
\hline 1050 & 102,2 \\
\hline 1120 & 106,2 \\
\hline 1130 & 112,5 \\
\hline 1510 & 153,8 \\
\hline 1240 & 124,4 \\
\hline 1370 & 134,5 \\
\hline 1170 & 114,0 \\
\hline 1090 & 101,2 \\
\hline 1230 & 117,9 \\
\hline 1260 & 130,4 \\
\hline
\end{tabular}

\begin{tabular}{|c|c|}
\hline $\begin{array}{c}<, 045 \\
\text { mm } \\
\text { (\%) Malvern }\end{array}$ & $\begin{array}{c}<\mathbf{0 , 0 4 5} \mathbf{~ m m} \\
\text { (\%) } \\
\text { Industrial }\end{array}$ \\
\hline 69,4 & 60,8 \\
\hline 69,0 & 59,3 \\
\hline 64,2 & 54,7 \\
\hline 72,8 & 64,8 \\
\hline 66,2 & 58,1 \\
\hline 69,4 & 60,5 \\
\hline 73,1 & 67,3 \\
\hline 70,9 & 62,3 \\
\hline 72,4 & 64,4 \\
\hline 63,8 & 54,2 \\
\hline 69,3 & 61,3 \\
\hline 66,1 & 58,0 \\
\hline 67,4 & 59,2 \\
\hline 64,2 & 54,7 \\
\hline 67,0 & 57,4 \\
\hline 69,3 & 62,7 \\
\hline 70,5 & 62,0 \\
\hline 66,8 & 57,9 \\
\hline 71,4 & 64,2 \\
\hline 64,3 & 55,3 \\
\hline 63,4 & 54,5 \\
\hline 66,8 & 59,3 \\
\hline 78,5 & 73,5 \\
\hline 71,0 & 63,7 \\
\hline 73,1 & 65,9 \\
\hline 79,1 & 74,8 \\
\hline 66,7 & 58,9 \\
\hline 76,6 & 69,7 \\
\hline 67,6 & 58,2 \\
\hline 68,3 & 60,8 \\
\hline 72,2 & 66,5 \\
\hline
\end{tabular}

Tabela 3. Valores para estabelecer correlações

\begin{tabular}{|c|c|c|c|}
\hline $\begin{array}{l}<0,045 \mathrm{~mm} \\
\text { (\%) Alpine }\end{array}$ & $\begin{array}{c}<0,045 \mathrm{~mm} \\
(\%) \\
\text { Industrial }\end{array}$ & $\begin{array}{c}\text { S.E. }\left(\mathrm{cm}^{2} / \mathrm{g}\right) \\
\text { Permeabilimetro }\end{array}$ & $\begin{array}{l}\mathrm{SE}\left(\mathrm{m}^{2} / \mathrm{kg}\right) \\
\text { Industrial }\end{array}$ \\
\hline 85,2 & 60,8 & 1574 & 111,3 \\
\hline 80,5 & 54,7 & 1401 & 101,0 \\
\hline 88,0 & 64,8 & 1471 & 104,8 \\
\hline 82,8 & 58,1 & 1693 & 121,3 \\
\hline 85,7 & 60,5 & 1824 & 136,2 \\
\hline 87,9 & 67,3 & 1659 & 122,6 \\
\hline 85,9 & 62,3 & 1796 & 130,4 \\
\hline 86,8 & 64,4 & 1376 & 100,7 \\
\hline 85,1 & 61,3 & 1612 & 118,9 \\
\hline 83,5 & 59,2 & 1528 & 111,5 \\
\hline 829 & $\frac{15}{547}$ & 1538 & 112,2 \\
\hline$\frac{02,5}{84,3}$ & $\frac{54,1}{574}$ & 1326 & 100,5 \\
\hline$\frac{04,3}{877}$ & 61,4 & 1584 & 112,4 \\
\hline$\frac{81,1}{89}$ & 64,2 & 1796 & 132,0 \\
\hline 82,1 & 55,3 & 1286 & 100,3 \\
\hline 81,7 & 54,5 & 1977 & 140,3 \\
\hline 84,6 & 59,3 & 1300 & 102,2 \\
\hline 92,5 & 73,5 & 1471 & 106,2 \\
\hline 87,7 & 63,7 & 2110 & 153,8 \\
\hline 89,5 & 65,9 & 1579 & 124,4 \\
\hline 84,3 & 58,9 & 1810 & 134,5 \\
\hline 86,9 & 61,2 & 1480 & 114,0 \\
\hline 84,9 & 60,8 & 1448 & 113,4 \\
\hline 81,8 & 58,0 & 1937 & 140,2 \\
\hline 87,5 & 64,9 & 1289 & 101,2 \\
\hline 87,4 & 66,5 & 1538 & 117,9 \\
\hline
\end{tabular}

Das tabelas 2 e 3 acima foram extraídos os valores para compor as correlações em pares conforme descrição e tabelas abaixo:

- Calibração de Superfície Específica (S.E.): S.E. Malvern $\left(\mathrm{cm}^{2} / \mathrm{g}\right)$ X S.E. Equipamento Industrial $\left(\mathrm{m}^{2} / \mathrm{kg}\right)$;

- Calibração de Granulometria passante em 0,045 mm: \% <0,045mm Malvern X $\%<0,045 \mathrm{~mm}$ Equipamento Industrial;

- Correlação de Superfície Específica (S.E.): S.E Permeabilímetro $\left(\mathrm{cm}^{2} / \mathrm{g}\right) X$ S.E. Equipamento Industrial $\left(\mathrm{m}^{2} / \mathrm{kg}\right)$;

- Calibração de Granulometria passante em 0,045 mm: \% <0,045mm Alpine X $\%<0,045 \mathrm{~mm}$ Equipamento Industrial. 


\subsection{Verificação de Calibração}

A verificação de calibração foi realizada através de gráficos de dispersão e linha onde pôde-se avaliar o grau de correlação entre as análises realizadas pelo equipamento industrial com as analisadas no laboratório pelo mesmo método.

\subsubsection{Calibração de superfície específica}

De posse dos dados da tabela 2 foi possível verificar o grau de correlação entre o equipamento industrial e o equipamento de laboratório, Malvern, para superfície específica gerando os gráficos abaixo. Foi constatado que o equipamento está calibrado para leitura de superfície específica pois, o coeficiente de correlação linear $\left(r_{x y}\right)$ encontrado foi de 0,98 com qualidade do ajuste $\left(R^{2}\right)$ de 0,96 conforme apresentado na figura 13.

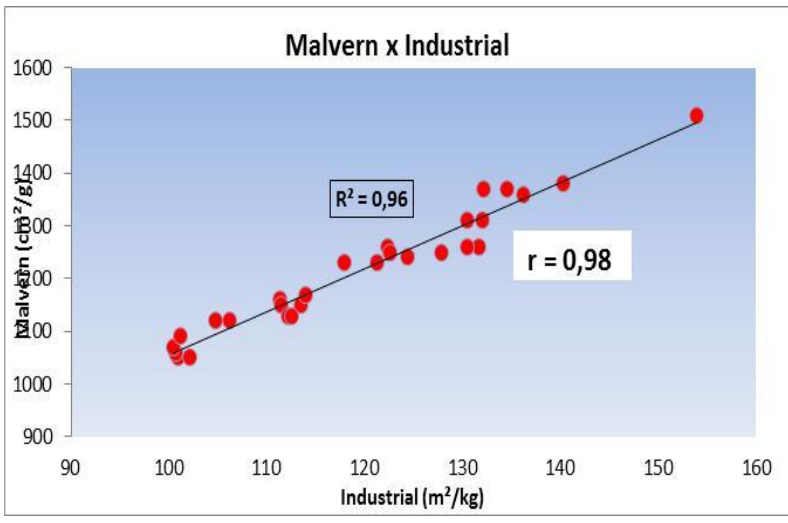

Figura 13. Dispersão Malvern $x$ Industrial - S.E

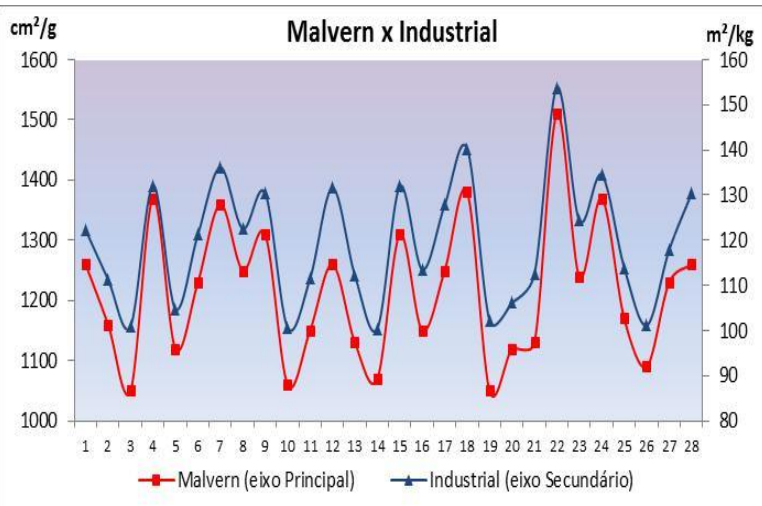

Figura 14. Linear Malvern $x$ Industrial - S.E

\subsubsection{Calibração de Granulometria}

Através dos dados da tabela 2 foi possível verificar o grau de correlação entre o equipamento industrial e o equipamento de laboratório, Malvern, para granulometria gerando os gráficos abaixo. Foi constatado que o equipamento está calibrado para leitura de granulometria passante em $0,045 \mathrm{~mm}$ pois, o coeficiente de correlação linear $\left(r_{x y}\right)$ encontrado foi de 0,98 com qualidade do ajuste $\left(R^{2}\right)$ de 0,97 conforme apresentado na figura 15.

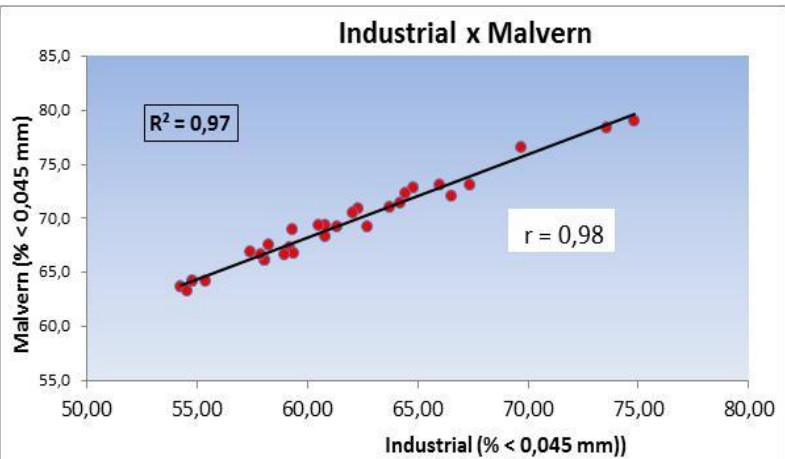

Figura 15. Dispersão Malvern $\mathrm{x}$ Industrial $<0,045$

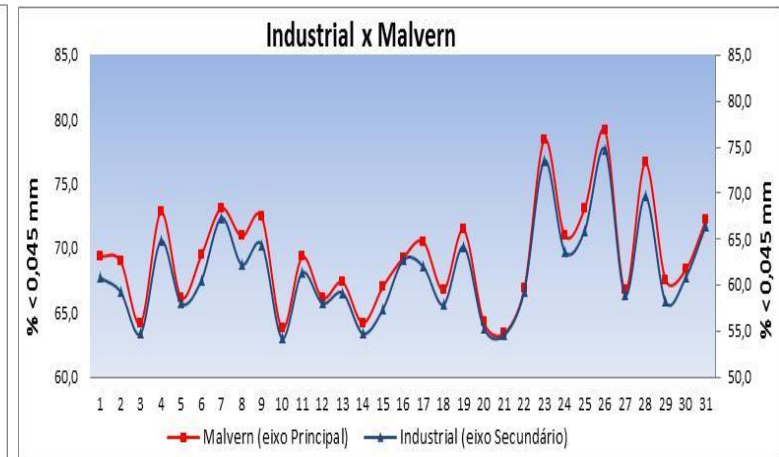

Figura 16. Linear Malvern $\mathrm{x}$ Industrial $<0,045$

\subsection{Estabelecimento de Correlação}

O estabelecimento de correlações foram realizadas através de gráficos de dispersão e linha onde pôde-se avaliar o grau de correlação e gerar equações de correlação

* Contribuição técnica ao $44^{\circ}$ Seminário de Redução de Minério de Ferro e Matérias-primas, $15^{\circ}$ Simpósio Brasileiro de Minério de Ferro e $2^{\circ}$ Simpósio Brasileiro de Aglomeração de Minério de Ferro, 15 a 18 de setembro de 2014, Belo Horizonte, MG, Brasil. 
entre as análises realizadas pelo equipamento industrial com as analisadas no laboratório por métodos diferentes.

\subsubsection{Correlação de granulometria}

De posse dos dados da tabela 3 foi possível verificar o grau de correlação entre o equipamento industrial e o equipamento de laboratório, Alpine, para granulometria gerando os gráficos abaixo, foi constatado que existe uma forte correlação para leitura de granulometria passante em $0,045 \mathrm{~mm}$ pois, o coeficiente de correlação linear $\left(r_{x y}\right)$ encontrado foi de 0,95 com qualidade do ajuste $\left(R^{2}\right)$ de 0,91 , desta forma conforme apresentado na figura 17, foi possível estabelecer a seguinte equação de correlação: Alpine $(\%<0,045 \mathrm{~mm})=0,58$ * (Valor industrial $)(\%<0,045 \mathrm{~mm})+49,99$.

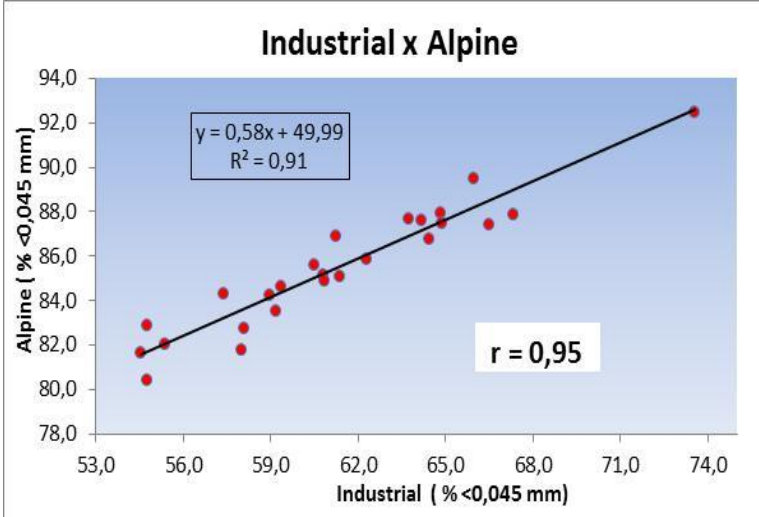

Figura 17. Dispersão Alpine $x$ Industrial <0,045

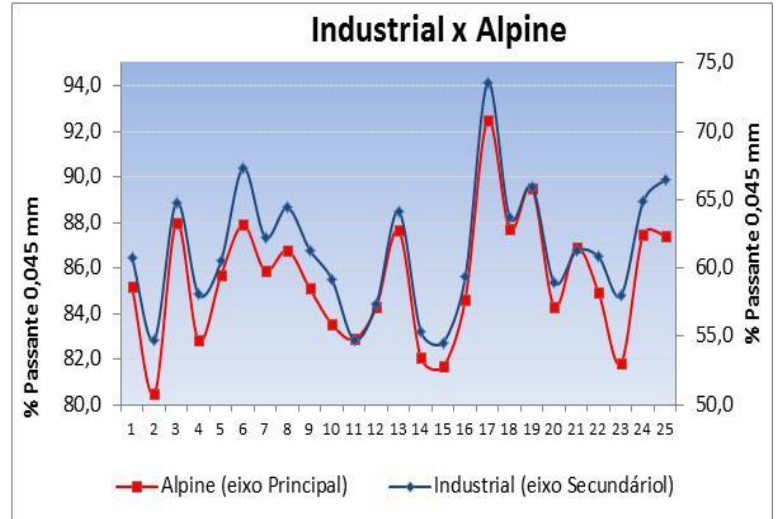

Figura 18. Linear Alpine $x$ Industrial $<0,045$

\subsubsection{Correlação de superfície específica}

Através dos dados da tabela 3 foi possível verificar o grau de correlação entre o equipamento industrial e o equipamento de laboratório, permeabilímetro, para superfície específica gerando os gráficos abaixo, foi constatado que existe uma forte correlação para leitura de superfície específica pois, o coeficiente de correlação linear $\left(r_{x y}\right)$ encontrado foi de 0,97 com qualidade do ajuste $\left(R^{2}\right)$ de 0,95 , desta forma conforme apresentado na figura 19, foi possível estabelecer a seguinte equação de correlação: Permeabilímetro $\left(\mathrm{cm}^{2} / \mathrm{g}\right)=14,50$ * $\left(\right.$ Valor industrial) $\left(\mathrm{m}^{2} / \mathrm{kg}\right)-115,61$.

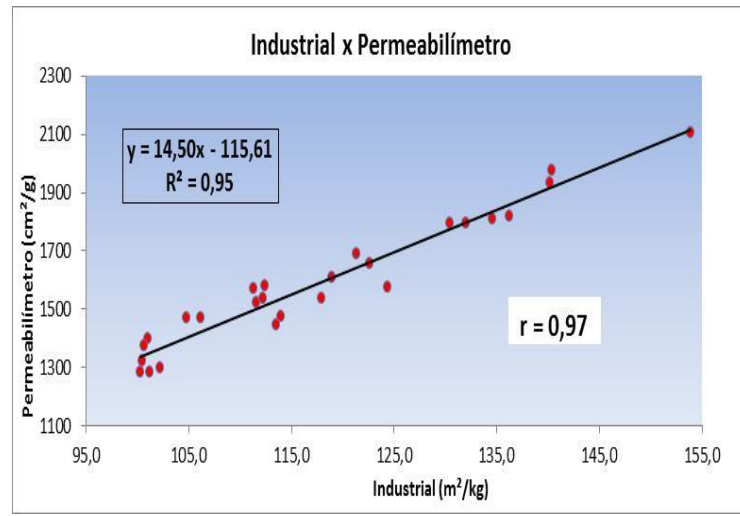

Figura 19. Dispersão Alpine $x$ Industrial - S.E.

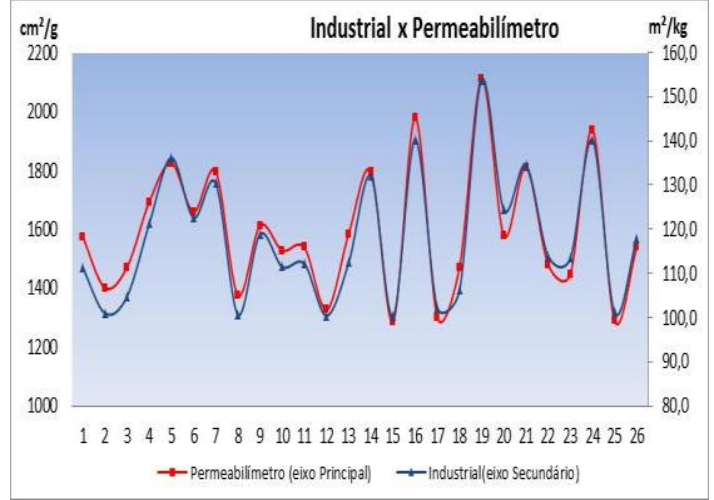

Figura 20. Linear Alpine $x$ Industrial - S.E.

\subsubsection{Validação das equações de correlação}

Para validação das equações de correlação primeiramente foram subtraídos os valores tais quais lidos pelo equipamento industrial dos valores lidos pelos equipamentos de laboratório, inicialmente foi encontrado uma diferença média de

\footnotetext{
* Contribuição técnica ao $44^{\circ}$ Seminário de Redução de Minério de Ferro e Matérias-primas, 15오 Simpósio Brasileiro de Minério de Ferro e 2ํ Simpósio Brasileiro de Aglomeração de Minério de Ferro, 15 a 18 de setembro de 2014, Belo Horizonte, MG, Brasil.
} 
24,18 pontos percentuais com desvio padrão de 2,1 para granulometria e $410 \mathrm{~cm}^{2} / \mathrm{g}$ com desvio padrão de 101 para superfície específica na mesma unidade de medida, após a confecção das equações foi realizado o mesmo procedimento e desta vez 0 valor médio encontrado foi de 0,00 pontos percentuais com desvio padrão de 0,8 para granulometria e $-14 \mathrm{~cm}^{2} / \mathrm{g}$ com desvio padrão de 85 para superfície específica na mesma unidade. As figuras 21 e 22 ilustram as diferenças antes e depois de aplicada as equações de correlação.

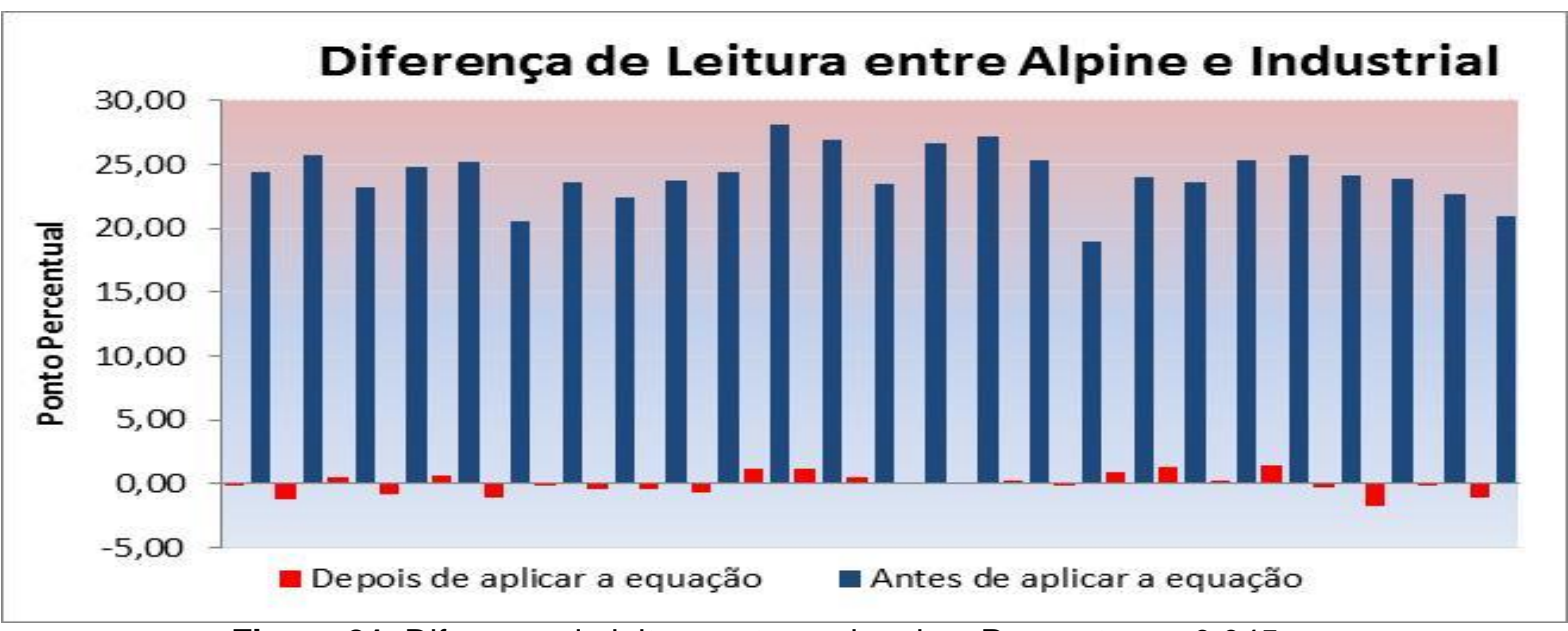

Figura 21. Diferença de leitura antes e depois - Passante em 0,045 mm

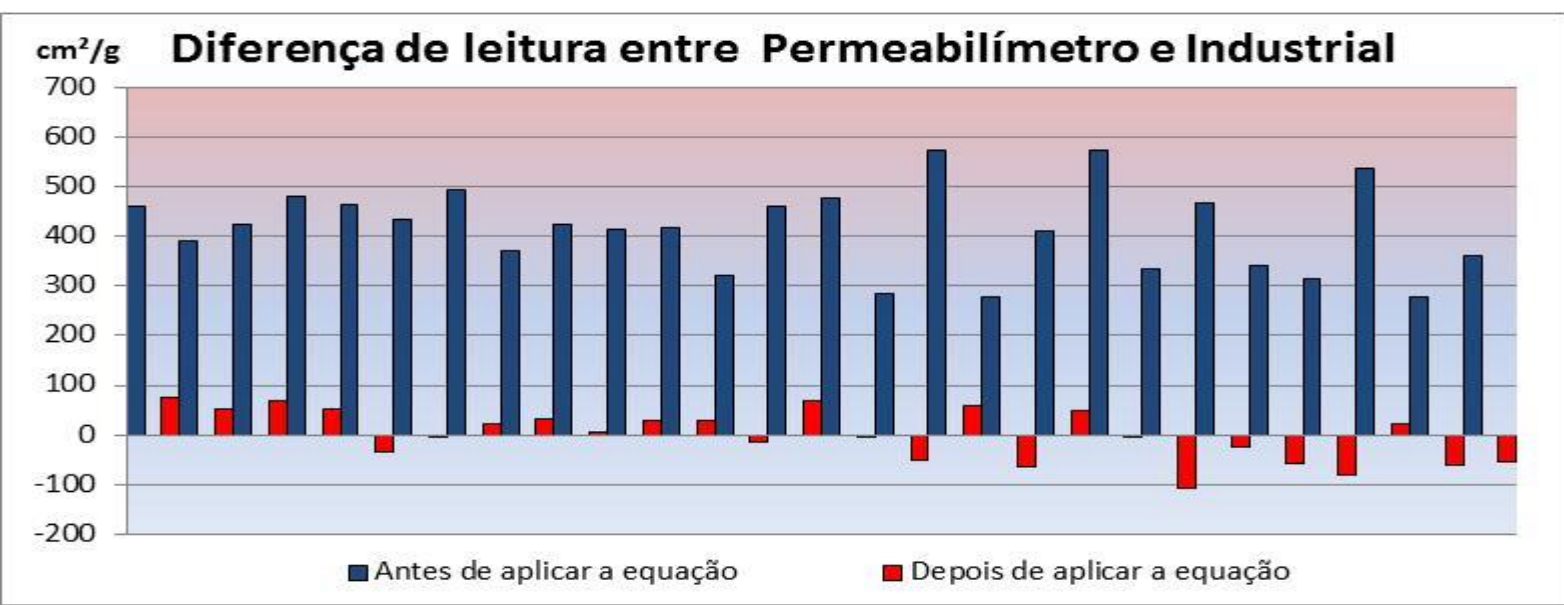

Figura 22. Diferença de leitura antes e depois - Superfície específica

\section{CONCLUSÃO}

A metodologia aplicada no trabalho foi satisfatória e possibilitou atingir o objetivo do estudo.

Com este trabalho pôde-se verificar que o equipamento industrial para medição de superfície específica e granulometria estudado está calibrado;

Foi estabelecida uma correlação entre a leitura do equipamento industrial com o equipamento de laboratório, Alpine, para as análises de Granulometria $<0,045 \mathrm{~mm}$ regida pela seguinte equação: Alpine $(\%<0,045 \mathrm{~mm})=0,58$ * (Valor industrial) $(\%<$ $0,045 \mathrm{~mm})+49,99$.

Foi estabelecida uma correlação entre a leitura do equipamento industrial com o equipamento de laboratório, permeabilímetro, para as análises de Superfície

\footnotetext{
* Contribuição técnica ao 44ํ Seminário de Redução de Minério de Ferro e Matérias-primas, $15^{\circ}$ Simpósio Brasileiro de Minério de Ferro e $2^{\circ}$ Simpósio Brasileiro de Aglomeração de Minério de Ferro, 15 a 18 de setembro de 2014, Belo Horizonte, MG, Brasil.
} 
Específica regida pela seguinte equação: Permeabilímetro $\left(\mathrm{cm}^{2} / \mathrm{g}\right)=14,50$ * $($ Valor industrial) $\left(\mathrm{m}^{2} / \mathrm{kg}\right)-115,61$.

Estas mesmas equações foram utilizadas em outros equipamentos industriais para condições semelhantes de moagem e também se mostraram satisfatórias.

\section{Agradecimentos}

Ao Caio pelo Comprometimento e Dedicação.

A Equipe da Usina Piloto (Catia, Sidney, Everaldo, Ana Paula e Nádia) pela Presteza e Agilidade nas análises.

A Tatiane Alvarenga pelas trocas de Experiências.

A Equipe da de operação das Usinas I a IV da Vale por disponibilizar os moinhos para teste.

A Equipe da Unidade Técnica das Usinas I a IV da Vale pelo Incentivo e Apoio.

\section{BIBLIOGRAFIA}

1 Schneider CL, Souza AS. 2004 [acesso em 09/05/2014]; 2; 13-17. Disponível em http://www.abmbrasil.com.br/materias/download/1262.pdf.

2 Penternell LA. Intervalo de confiança; 2008; NIF162; capítulo 9.

3 Souza, A. Coeficiente de Correlação Linear de Pearson ;[acesso em 10/05/2014]; 1-10. Disponível em http://www.aurea.uac.pt/pdf_MBA/coef_correl_Pearson.pdf;

4 Outotec. Manual de operação analisador de granulometria PSI 500. 2012.

5 Alvarenga T, Souza AP, Stegmiller L, Aires M, Thomazini A, Nunes L, Lorencini M; Relatório do teste e calibração do PSI e determinação de curvas de correlação; Relatório interno Vale; 2013; 1:1-18.

6 Pena EQ; Caracterização dos parâmetros Intríncicos de Porosidade e Superfície Específica de Pellet Feed; Resumo de dissertação de mestrado; 2002 [Acesso em 01/05/2014]; 1. Disponível em:

http://www.redemat.ufop.br/index.php?option=com_content\&view=article\&id=581:caract eriza-dos-partros-intrecos-de-porosidade-e-superfe-especca-de-pelletfeed\&catid=36:2002\& Itemid $=64$

* Contribuição técnica ao 44 Seminário de Redução de Minério de Ferro e Matérias-primas, $15^{\circ}$ Simpósio Brasileiro de Minério de Ferro e $2^{\circ}$ Simpósio Brasileiro de Aglomeração de Minério de Ferro, 15 a 18 de setembro de 2014, Belo Horizonte, MG, Brasil. 